\title{
INVESTIGATION OF THE STRESSES AND INTERACTION EFFECTS OF NOZZLE- CYLINDER INTERSECTIONS WHEN SUBJECT TO MULTIPLE EXTERNAL LOADS
}

\author{
Murat Bozkurt \\ PhD Student \\ Department of Mechanical \\ and Aerospace Engineering \\ University of Strathclyde \\ 75 Montrose Street, G1 1XJ \\ Glasgow, UK \\ E-mail: murat.bozkurt@strath.ac.uk
}

\author{
Professor David Nash \\ Deputy Head of Department \\ Department of Mechanical \\ and Aerospace Engineering \\ University of Strathclyde \\ 75 Montrose Street, G1 1XJ \\ Glasgow, UK \\ E-mail: d.nash@strath.ac.uk
}

\author{
Dr Asraf Uzzaman \\ Knowledge Exchange Associate \\ Department of Mechanical \\ and Aerospace Engineering \\ University of Strathclyde \\ 75 Montrose Street, G1 1XJ \\ Glasgow, UK \\ E-mail: asraf.uzzaman@strath.ac.uk
}

\section{ABSTRACT}

Analyzing and solving the problem of practical cylindercylinder pressure vessel intersections is challenging when using a finite element approach. Although numerous theoretical and finite element solutions have been developed for the cylindercylinder intersection problem, there remains the requirement for an updated, innovative model which takes account of all practical as-fabricated features including fillets and crotch corner ground radii. This study presents the development of a suitable model, based on the results of a parametric macro study, which is able to compare all of these operations on a single, high fidelity model. This study considers a cylindrical pressure vessel with a single nozzle connection without reinforcement plate and examines the maximum stress values in the nozzle-shell intersection area (crotch corner) under the various loads applied to the nozzle. Additionally, internal pressure and external load actions on the nozzle, including effects of circumferential, torsional, and longitudinal moments are compared using a suitable finite element approach. Furthermore, equations and solutions for external loads in spherical and cylindrical shells are given in WRC Bulletins 107 and 537. Therefore, comparisons with the results obtained from these are made for validation purposes and the overall impact of the new as-built approach is presented.

Keywords: Pressure vessel, Nozzle, External load, NozzleCylinder intersection, FEA

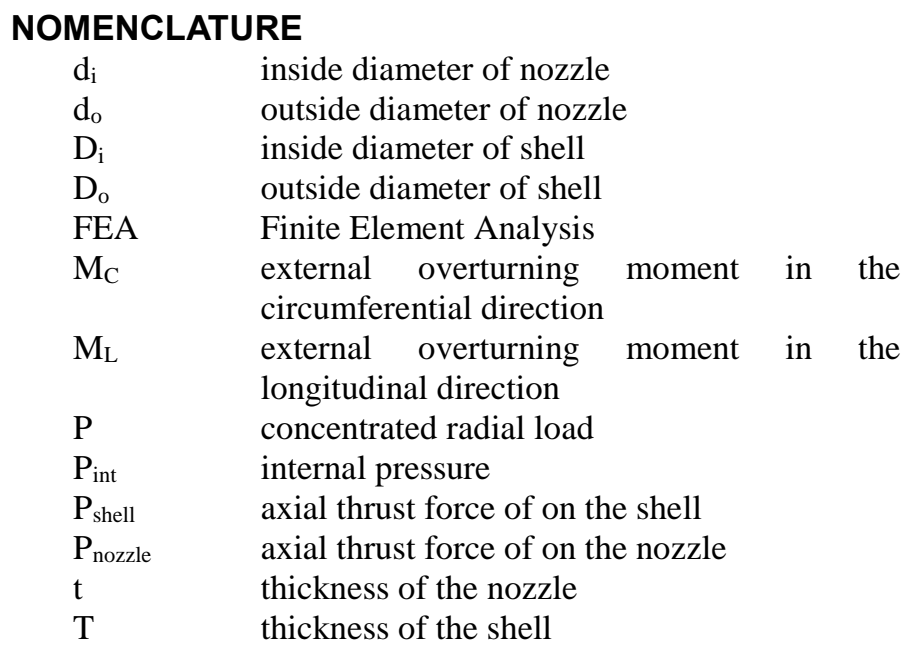




\section{INTRODUCTION}

In pressure vessel applications, the existing structures can be subject to various loads. These include the main internal pressure, but also external global loads and local loads which comprise various forces and moments. In such applications, if the necessary precautions are not taken and as a result of the stresses on the structures, significant damage can arise. In particular, WRC 107 [1] and WRC 537 [2], which is a more exact implementation of the WRC 107, offer the necessary formulas and diagrams for spherical and cylindrical pressure vessels under external loads. This approach is based on shell theory and does not take into account of the opening formed by the nozzle intersection. This is encapsulated in WRC 297 [3], which too relies on shell theory. At the junction, this method has deficiencies and cannot fully represent the geometry at the junction.

In addition, stresses from external loads can be calculated by methods such as PD 5500 Annex G [4] or Wordsworth [5] as well. However, the results obtained from all these shell theory methods can vary, albeit the differences are small. In general, these methods provide solutions and evaluations for a range of vessel nozzle geometries. They also claim that each method provides the most accurate results. Dekker [6] shows the differences between the methods mentioned in the study and provides comparison methods.

In other studies, Dekker et al. [7] have undertaken several finite element analyses to calculate stresses on the nozzle walls rather than stresses on the shell. The reason for this is that the local load stress calculation methods have important differences between each other. As a result of these findings, researchers formulated the 'modified improved shrink ring method' and introduced a new approach.

One of the problems that is frequently encountered in pressure vessels is cracking and breaking. Sedighiani et al. [8] examined mode-II, mode-III and T stresses instead of mode-I stresses for life analysis of failed cylindrical vessels nozzle junctions. For these mixed tensile loads, a 3-dimensional elastic end member method was used to calculate the tensile strength under different stresses. Stress intensity factor and T-stress were seen to be associated with many factors affecting the fracture event. In the end, this study showed that in many cases the effect of T-stress with the mode-II factor was negligible.

In another study related to nozzle cylinder connections exposed to overloads, Andrade et al. [9] examined the stresses due to external loads. For this purpose, they have introduced a nozzle-vessel model without the use of reinforcement plates. In this study, they compared the stress results obtained from the model subjected to external loads by using WRC 107, WRC 297 and finite element method. According to the results obtained, it is stated that the analyzed model is safe according to the mentioned bulletins, however this does not lead to a universal solution for industry.

Furthermore, there are many proprietary computer programs that provide code implementations to the problems related to nozzle shell combinations. Although the approximations are generally very similar, there are some differences in the results. Chandiramani et al. [10] have obtained a comparative study by comparing the solutions they obtained with finite element method to the basic calculations in Bulletin 297 and Bulletin 537. The results of the comparison were also shown in 3D graphics and they tried to show the differences in more detail.

Pad reinforcements are widely used in many pressure vessel and piping connection systems to provide reinforcement of the opening and reduce overall stresses. Fang et al. [11] attempted to compare strength behaviors in cylindrical shells with and without pad reinforcement under external loads. As a result of the comparisons, it was seen that there was a significant increase in the strength of the vessels with pad reinforcement. Besides, the maximum elastic stress and stress ratio has decreased significantly.

In this study, a new high fidelity model has been developed to take account of the maximum stresses around the crotch corner of the nozzle shell connections exposed to combined loads. The ultimate goal is to develop a new model that will be applicable for the full range of geometries used by industry and provide a universal approach to local loads for nozzle cylinder junctions.

\section{STATEMENT OF THE PROBLEM}

In the case of pressure vessel problems, the highest stresses often occur in the nozzle cylinder intersection regions. Accurate determination of these stress values is of great importance in terms of taking necessary precautions in design and future fatigue assessment. Finite element analysis is one of the most commonly used numerical procedures. Although all stress values on the vessels with finite element method can be determined very easily, because of the differences in the method applied, the results are not completely aligned. The aim of this study is to create a high fidelity model which can respond to different shapes and applications for nozzle shell combinations with different thickness ratios. At this time, the scope of this problem is for a linear elastic solution establishing maximum stress values around the crotch corner which shall be taken as basis for the model.

\section{FINITE ELEMENT MODEL DEVELOPMENT}

2.1. General

In this section, a model highlighting the interaction of cylinder-nozzle under various loads will be developed using the finite element method. Chandiramani's study [10] is used as a basis for model development study. In this study, only the results without reinforcement plate are taken from Chandiramani's study. The finite element program ANSYS is used. After model verification, the effect of outside welding fillet geometry 
dimensions in nozzle-shell intersections is investigated along with a parametric study and the resulting stresses is re-examined with and without the addition of an inner fillet. In the end, the model that gives the most plausible results is investigated further with the effect of multiple external load combinations which is the main subject of the study.

\subsection{Geometry}

In order to show the model to be used gives the correct results, all the assumptions and dimensions of model will be taken exactly from Chandiramani's study. The proportion of the nozzle diameter with the shell diameter is 0.5 for all models. Whilst the model is restricted by one side, by means of boundary conditions, on the other hand axial movement will be allowed on the other side. Furthermore, since the whole model will be under the influence of the internal pressure, the movement against the thrust which will occur in the radial direction will be released. In addition, the axial thrust resulting from the internal pressure shall be applied separately to the nozzle and the shell. Since the welding dimensions are not given in the current study, a separate study is conducted to determine this. As indicated, peak stresses are ignored. A perspective view of the model is shown in Figure 1.
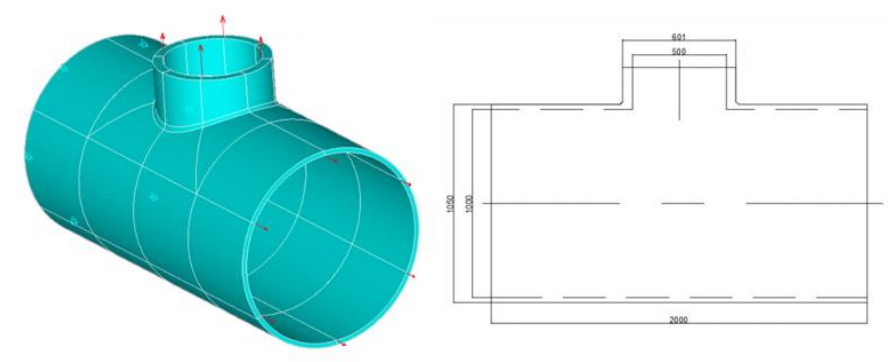

FIGURE 1: MODEL OF THE NOZZLE - CYLINDER JUNCTIONS

\subsection{Material Properties}

In the analysis to be carried out, SA-516 Grade 70 Carbon steel pressure vessel plates is used as the shell material. The value of Young's modulus is 200GPa and Poisson's ratio is 0.29. ASTM A266 Grade 2 Carbon Steel is used for the nozzle material. The value of Young's modulus is 190GPa and Poisson's ratio is 0.29 . The welding material is assumed to be the same as the nozzle.

\subsection{Element Type and Mesh Sensitivity}

Figure 2 shows details of a typical finite element mesh of the cylinder-nozzle interaction noting the inside diameter of nozzle is always the half of vessel inside diameter. For a model with an inner diameter of $500 \mathrm{~mm}$, the element size was $30 \mathrm{~mm}$, and for the remaining cases it was $50 \mathrm{~mm}$. Furthermore, the element type was chosen as SOLID186 which is a higher order 3-D with 20-node solid element.

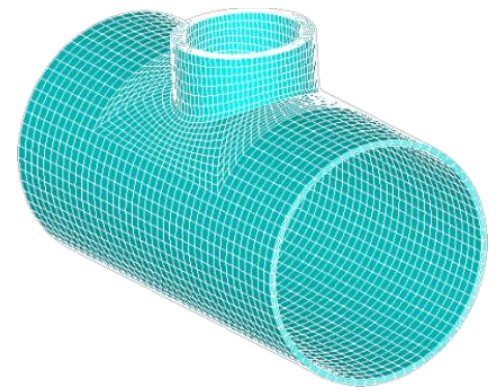

\section{FIGURE 2: PERSPECTIVE VIEW OF THE MESHED MODEL}

As the maximum stress variation in the analysis is the region of the nozzle-shell combination, a mesh sensitivity analysis is needed for this region. For this reason, the effect of the number of elements extending along the thickness of the nozzle to the stress values was examined. The nozzle thickness is divided into $1,2,4,6,8$ and 10 elements in each analysis. The distributions of the elements for using 2 and 4 elements along the nozzle are shown in Figure 3 and Figure 4.
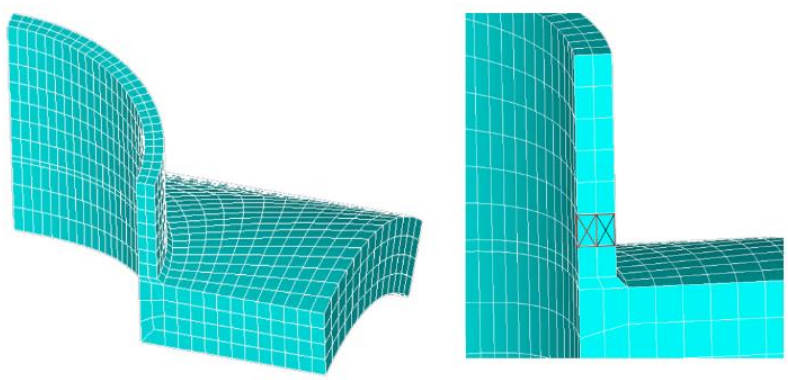

FIGURE 3: APPLYING 2 ELEMENTS THROUGHOUT THE NOZZLE THICKNESS
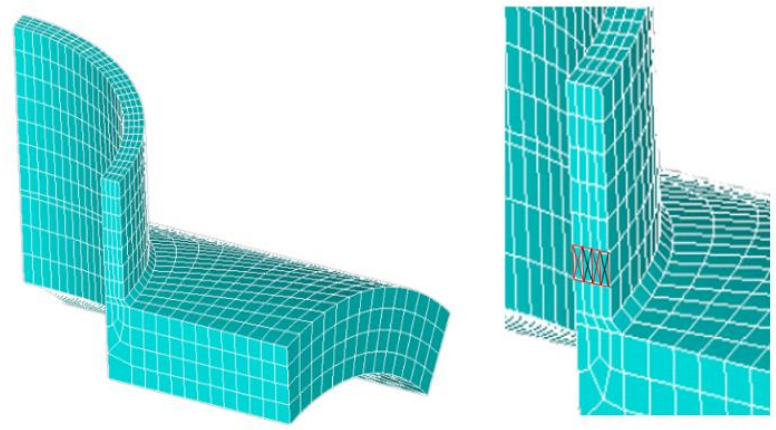

FIGURE 4: APPLYING 4 ELEMENTS THROUGHOUT THE NOZZLE THICKNESS

As a result of the mesh sensitivity analysis carried out, there are no significant differences in their stress distributions and values. The maximum difference between the stress values occurred when 2 elements were used throughout the nozzle. This difference is less than $1 \%$. The results are shown in the Figure 5. 


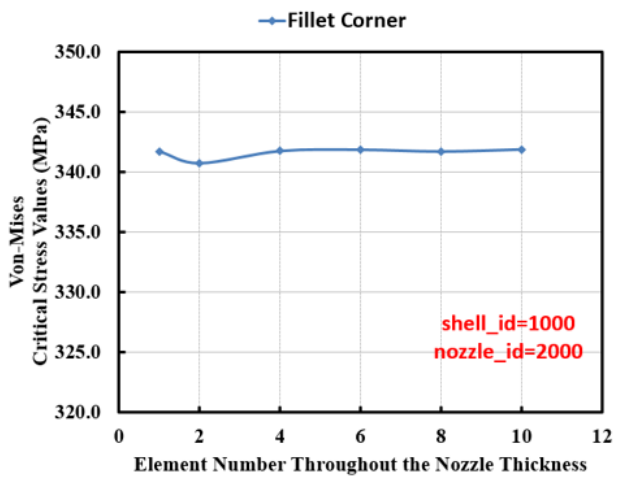

FIGURE 5: VARIATION OF STRESS VALUES ACCORDING TO ELEMENT NUMBERS

Although the results are very close, it seems that mesh distributions are more reasonable when 4 and 6 elements are used. For this reason, it was decided to use 6 elements throughout the nozzle thickness to meet a common point for future studies.

\subsection{Loading and Boundary Conditions}

In the analyses to be carried out, the boundary and the loading conditions are the same as that of the Chandiramani et al [10]. That is, while the model is restricted by one side in the yaxis, the axial direction is free to move from the other side. Also the movement of the cylinder and nozzle is allowed in the radial direction. Both the cylinder and nozzle are under internal pressure. Other than this, no loading condition will occur at this stage.

The models verified after the validation analysis are exposed to various external loads to be applied from the nozzle center point. There are no change in boundary conditions.

\subsection{Verification of Finite Element Model}

While the verification of the model was carried out, the stress results of zero percentage contribution to area from the shell were used since the use of reinforcing plate is not related to this study. In addition to the hand calculation, the stress values obtained by the finite element method were used in these processes. The peak stresses obtained by the finite element method were ignored. While these results were obtained, the value of internal pressure was taken as $8.5 \mathrm{MPa}$ as indicated in the study. The thrust forces on the nozzle and cylinder with the effect of the internal pressure are also calculated by using formulas 1 and 2. Allowable and FEA stress results are given in the Figure 6 below.

$$
\begin{gathered}
P_{\text {shell }}=\frac{P_{i n t * D_{i}^{2}}}{\left(D_{0}^{2}-D_{i}^{2}\right)} \\
P_{\text {nozzle }}=\frac{P_{i n t} * d_{i}^{2}}{\left(d_{0}^{2}-d_{i}^{2}\right)}
\end{gathered}
$$

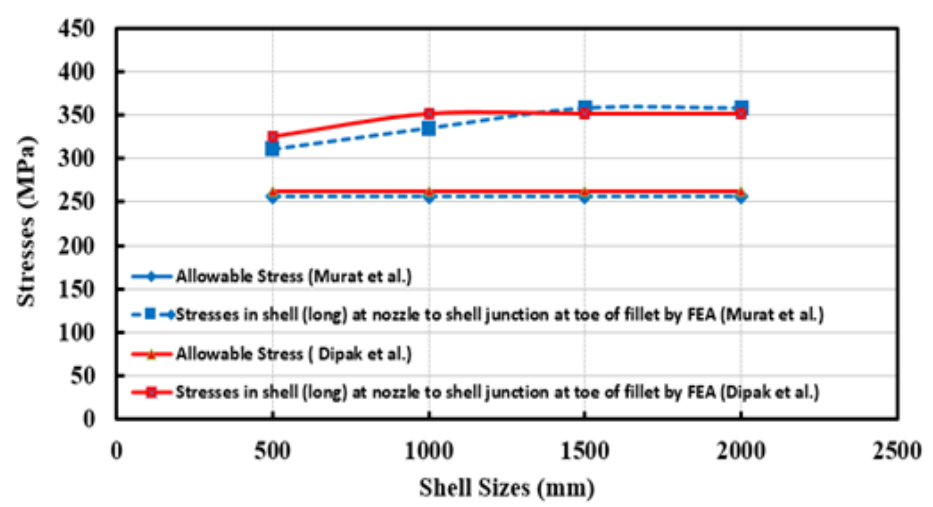

FIGURE 6: STRESSES (MPA) VS SHELL SIZES (MM) FROM SHELL

As can be seen from the Figure 6, the results obtained are very close to the current study and the model is therefore verified with these results. In the following steps, parametric studies are carried out and studies are performed to reduce the maximum stress values on the crotch corner.

\section{PARAMETRIC STUDY}

As a result of some parametric studies undertaken on the finite element model, it is predicted that the maximum stresses in the nozzle-cylinder junction (crotch corner) will be optimized and reduced. For this purpose, some modifications are applied on the model. Thereafter some external loading applications and combinations are examined. Parameter studies are performed in four discrete steps.

\subsection{Investigation of the Inner Fillet Applying Effects}

As noted, the ultimate target is to decrease the maximum critical stress values on the crotch corner by applying an inner fillet throughout the nozzle-cylinder intersection. This is commonly undertaken in industry. The representative image for the inner fillet application is shown in Figure 7. Analyses were carried out on cylinders having shells of $500 \mathrm{~mm}, 1000 \mathrm{~mm}$ and $2000 \mathrm{~mm}$ inside diameter. In total, some 69 analyses were completed for comparison. The main variable in this analysis is the ratio of the nozzle to vessel thickness $(\mathrm{t} / \mathrm{T})$.

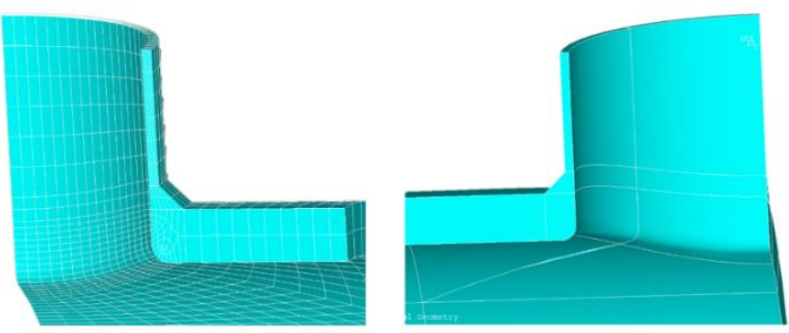

FIGURE 7: INNER FILLET APPLICATION

At the end of the analyses, results were compared for models with sharp corner, outside welding fillet and inner fillet. A representative image of each of the models is shown in Figure 8. 

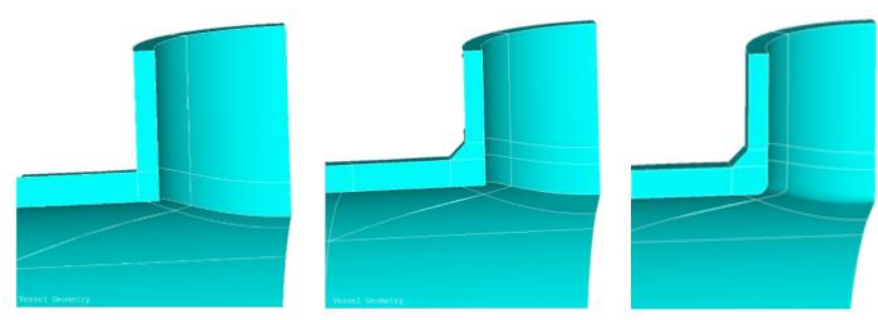

FIGURE 8: MODELS WITH SHARP CORNER, WELDING AND INNER FILLET

In all analyses, SA-516 Grade 70 Carbon Steel Pressure Vessel Plates have material properties of 200GPa Young Modulus material and ASTM A266 Grade 2 Carbon Steel has 190GPa Young Modulus material were used for shell and nozzle respectively. Six elements were applied throughout the nozzle thickness. The obtained maximum stress values and comparisons are given in the Figures 9-11.

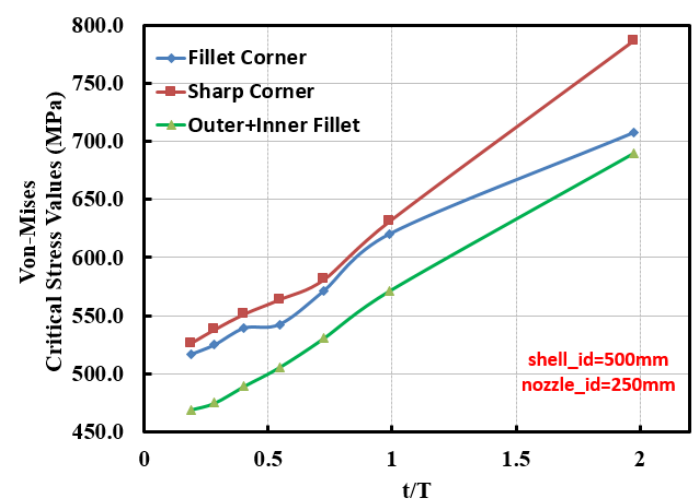

FIGURE 9: COMPARISON THE STRESS VALUES FOR THE VESSELS WITH 500MM INSIDE DIAMETER

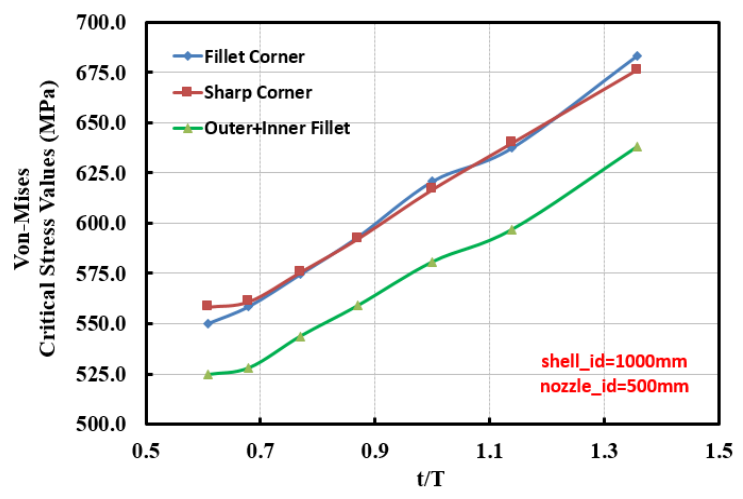

FIGURE 10: COMPARISON THE STRESS VALUES FOR THE VESSELS WITH 1000MM INSIDE DIAMETER

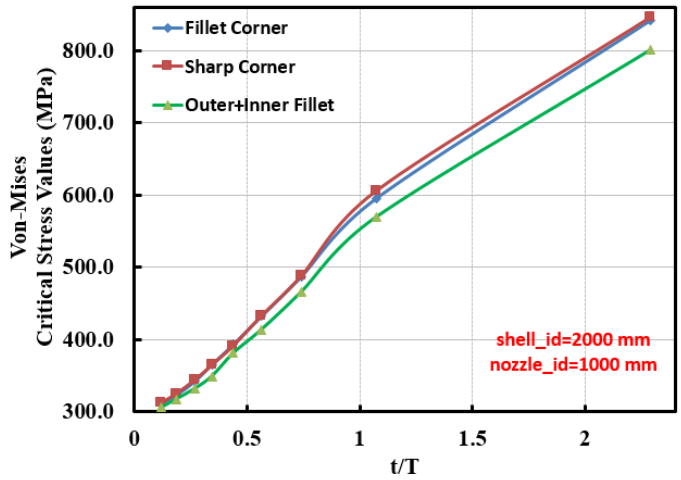

FIGURE 11: COMPARISON THE STRESS VALUES FOR THE VESSELS WITH 2000MM INSIDE DIAMETER

In the analysis carried out, the vessel dimensions were doubled each time from $500 \mathrm{~mm}$ to $1000 \mathrm{~mm}$ and from $1000 \mathrm{~mm}$ to $2000 \mathrm{~mm}$. When the graphs are examined, the outside fillet weld connection for a vessel with $500 \mathrm{~mm}$ inner diameter provides a $4 \%$ reduction in average at maximum critical stress values for each nozzle shell thickness ratio. However, when the vessel size is increased, the differences are $1.5 \%$ in average for vessels with $1000 \mathrm{~mm}$ inner diameter and the differences are less than $1 \%$ for vessels with $2000 \mathrm{~mm}$. Looking at the cases where the outer fillet weld and the inner fillet are applied at the same time, a reduction of about $10 \%$ for a $500 \mathrm{~mm}$ vessel and 5 percent for the other cases are obtained at the maximum stress values.

As such, it is obvious that the effect of the inner fillet application is more significant in reducing maximum stress values. In the analysis undertaken, the weld geometry and inner fillet dimensions were kept constant. It is therefore worth considering optimizing the junction by changing both the weld and fillet dimensions separately for any given case. Using this approach, the most reasonable parameters can be obtained for fillet applications at the nozzle-vessel intersections.

\subsection{Investigation of the Changing Outer Welding Fillet Dimension Effects}

In order to investigate the effect of outside fillet weld dimensions, the maximum stress values obtained were compared for the cylinder with an inner diameter of $2000 \mathrm{~mm}$ and the nozzle of $1000 \mathrm{~mm}$ inner diameter $\left(\mathrm{d}_{\mathrm{i}} / \mathrm{D}_{\mathrm{i}}=0.5\right) .15 \mathrm{~mm}, 30 \mathrm{~mm}$ and $45 \mathrm{~mm}$ width - length sizes are used as outer welding dimensions. The weld geometry with $15 \mathrm{~mm}$ leg length is given in the Figure 12. 


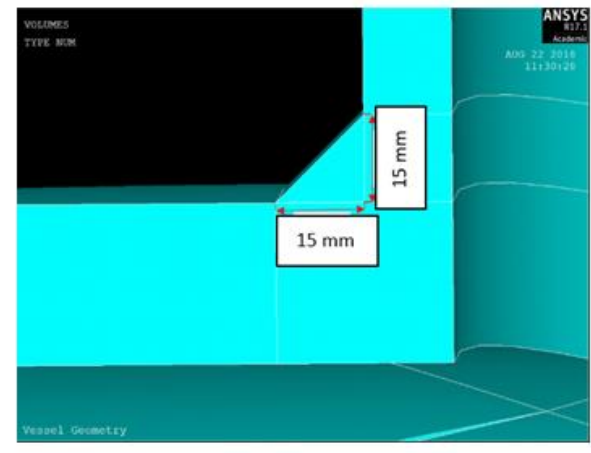

FIGURE 12: OUTSIDE FILLET WELD DIMENSIONS

Analyses were undertaken for 7 different thickness ratios $(t / T)$ and for 3 different welding sizes. The results can be seen in the Figure 13. As can be seen in the graph, only the variation of the fillet weld dimensions is not a factor that influenced considerably the stress values. As can be seen in the graph, the welding size increased by $15 \mathrm{~mm}$ for each case. In all cases, the stress values on the crotch corner were very close to each other and the difference between these values was less than 1 percent. Due to this reason, the same operation was applied in the inner fillet formed around the crotch corner.

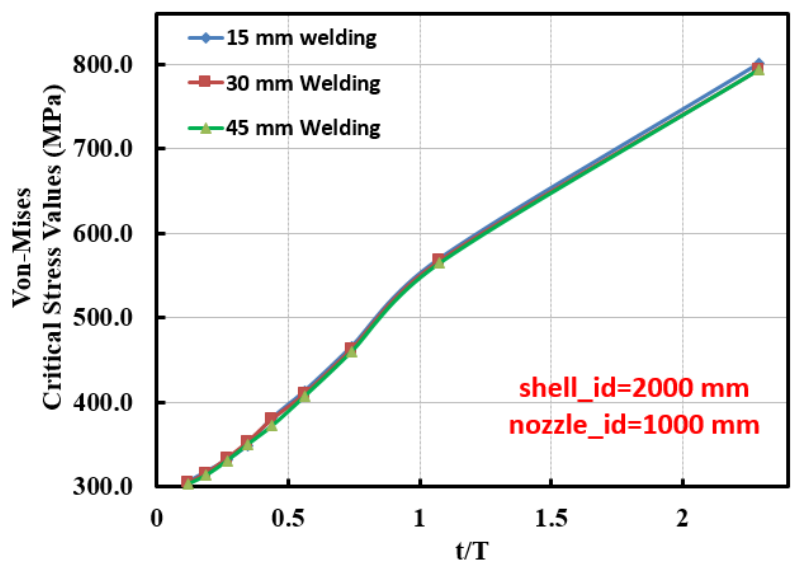

FIGURE 13: STRESS VALUES WHEN CHANGING OUTSIDE FILLET WELD SIZES

\subsection{Investigation of Changing Inner Fillet Dimension Effects}

It was stated previously that the changes in weld profile dimensions did not have a significant effect. As a result of the analysis obtained, it is proposed that the formation of the inner fillet may have more significant effects. In each successive analysis, the radius of the inner fillet was increased by $5 \mathrm{~mm}$ and the effects were compared.

If the model with a sharp corner is compared with a model with $5 \mathrm{~mm}$ internal fillet, when the thickness ratio between nozzle and shell is 0.97 , a $11.8 \%$ decrease is observed in the maximum stress values on the crotch corner. This ratio is the highest value obtained in the comparative analysis. In other values, an average difference of 9 percent was observed. Stress values continue to decrease when the fillet is applied greater than $5 \mathrm{~mm}$. The resulting maximum Von-Mises stress results are shown in Figure 14 with a graph.

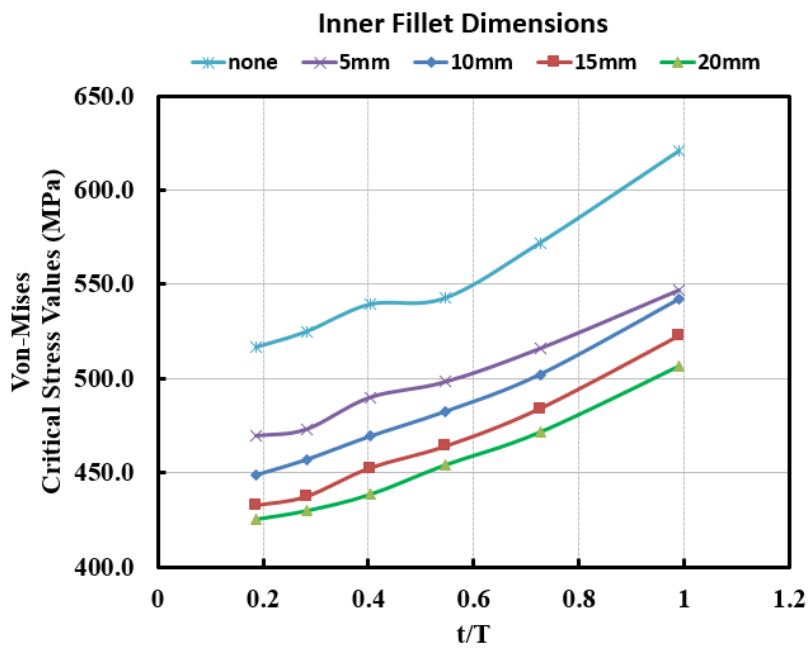

FIGURE 14: STRESS VALUES WHEN CHANGING INNER FILLET DIMENSIONS

As a consequence, this difference continues albeit at a diminishing rate. Finally, when the model having a sharp junction and a model with a $20 \mathrm{~mm}$ inner fillet are compared, the average stress is reduced by $18 \%$ in the maximum point. In the view of such information it is evident that the influence of internal fillet is more productive than welding to diminish stress values on cylinder- cylinder intersected cases.

\subsection{Multiple External Loads Applications}

For this study, the maximum stress values of the model under various loads will is considered for a single geometry configuration. The inner diameter ratios for the nozzle and cylinder are $d_{i} / D_{i}=0.5$, while the thickness ratio is taken as $t$ / $\mathrm{T}=0.24$. The weld profile has $15 \mathrm{~mm}$ leg length with an inner radius of $15 \mathrm{~mm}$ at the crotch corner.

Analyses were carried out in 5 stages while examining the external loads. These load combinations and magnitudes are given in the Table 1. In total, 6 analyses were performed for each case.

TABLE 1: APPLYING LOADS COMBINATIONS AND MAGNITUDES FOR EACH CASES

\begin{tabular}{|c|c|c|c|c|c|c|c|}
\hline & \multicolumn{6}{|c|}{ Loading Magnitudes } \\
\hline \multicolumn{2}{|c|}{ Analysis Number } & $1^{s t}$ & $2^{\text {nd }}$ & $3^{\text {rd }}$ & $4^{\text {th }}$ & $5^{\text {th }}$ & $\sigma^{\text {th }}$ \\
\hline \multirow{4}{*}{$\begin{array}{c}1^{s t} \\
\text { case }\end{array}$} & $\mathrm{P}_{\text {int }}(\mathrm{MPa})$ & 0.5 & 0.5 & 0.5 & 0.5 & 0.5 & 0.5 \\
\hline & $\mathrm{P}(\mathrm{kN})$ & 1 & 5 & 10 & 25 & 50 & 100 \\
\hline & $\mathrm{M}_{\mathrm{C}}(\mathrm{kNm})$ & - & - & - & - & - & - \\
\hline & $\mathrm{M}_{\mathrm{L}}(\mathrm{kNm})$ & - & - & - & - & - & - \\
\hline \multirow{4}{*}{$\begin{array}{c}2^{\text {nd }} \\
\text { case }\end{array}$} & $\mathrm{P}_{\text {int }}(\mathrm{MPa})$ & 0.5 & 0.5 & 0.5 & 0.5 & 0.5 & 0.5 \\
\hline & $\mathrm{P}(\mathrm{kN})$ & - & - & - & - & - & - \\
\hline & $\mathrm{M}_{\mathrm{C}}(\mathrm{kNm})$ & 1 & 5 & 10 & 25 & 50 & 100 \\
\hline & $\mathrm{M}_{\mathrm{L}}(\mathrm{kNm})$ & - & - & - & - & - & - \\
\hline
\end{tabular}




\begin{tabular}{|c|l|c|c|c|c|c|c|}
\hline \multirow{3}{*}{$\boldsymbol{3}^{\text {rd }}$} & $\mathrm{P}_{\text {int }}(\mathrm{MPa})$ & 0.5 & 0.5 & 0.5 & 0.5 & 0.5 & 0.5 \\
case & $\mathrm{P}(\mathrm{kN})$ & - & - & - & - & - & - \\
& $\mathrm{M}_{\mathrm{C}}(\mathrm{kNm})$ & - & - & - & - & - & - \\
& $\mathrm{M}_{\mathrm{L}}(\mathrm{kNm})$ & 1 & 5 & 10 & 25 & 50 & 100 \\
\hline \multirow{3}{*}{$\mathbf{4}^{\text {th }}$} & $\mathrm{P}_{\mathrm{int}}(\mathrm{MPa})$ & 0.5 & 0.5 & 0.5 & 0.5 & 0.5 & 0.5 \\
case & $\mathrm{P}(\mathrm{kN})$ & - & - & - & - & - & - \\
& $\mathrm{M}_{\mathrm{C}}(\mathrm{kNm})$ & 1 & 5 & 10 & 25 & 50 & 100 \\
& $\mathrm{M}_{\mathrm{L}}(\mathrm{kNm})$ & 1 & 5 & 10 & 25 & 50 & 100 \\
\hline \multirow{3}{*}{$5^{\text {th }}$} & $\mathrm{P}_{\text {int }}(\mathrm{MPa})$ & 0.5 & 0.5 & 0.5 & 0.5 & 0.5 & 0.5 \\
case & $\mathrm{P}_{(\mathrm{kN})}$ & 1 & 5 & 10 & 25 & 50 & 100 \\
& $\mathrm{M}_{\mathrm{C}}(\mathrm{kNm})$ & 1 & 5 & 10 & 25 & 50 & 100 \\
& $\mathrm{M}_{\mathrm{L}}(\mathrm{kNm})$ & 1 & 5 & 10 & 25 & 50 & 100 \\
\hline
\end{tabular}
15 below.

The representation of the cases analyzed is in the Figure

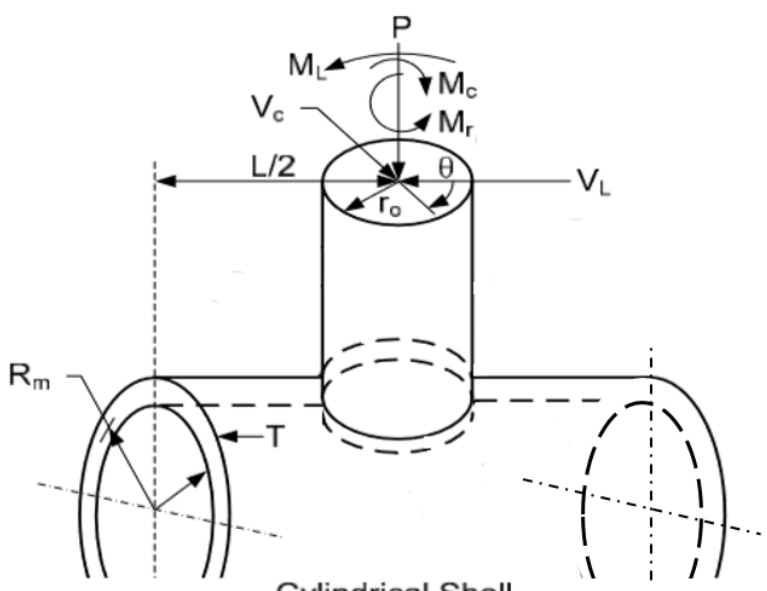

\section{Cylindrical Shell}

FIGURE 15: MULTIPLE EXTERNAL LOADING CONDITIONS

In order to apply the external loading conditions, link elements are located between the nozzle center and the nozzle edges. An applied form of link elements is shown in Figure 16. As a result of the use of these elements, centrally applied loading conditions can be simply added.

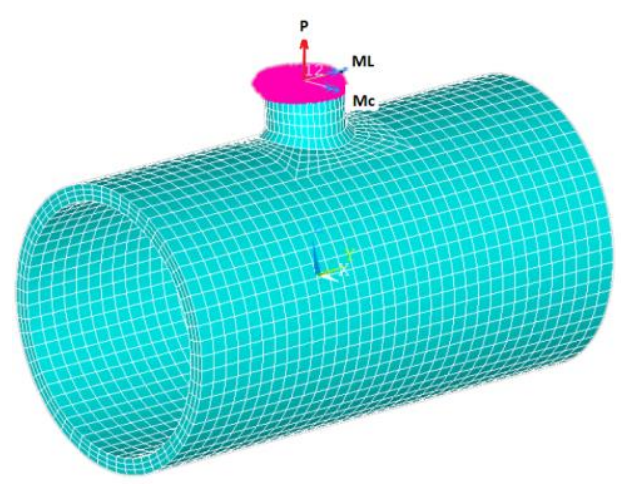

FIGURE 16: LINK ELEMENTS APPLICATIONS
The stress values obtained as a result of the study are plotted in the Figure 17. When the results obtained are taken into account, only the circumferential moment with the internal pressure and the only longitudinal moment effect have the nearly same stress results. In other cases, as the overload condition that affects the nozzle increases, the stress values also increase significantly as expected.

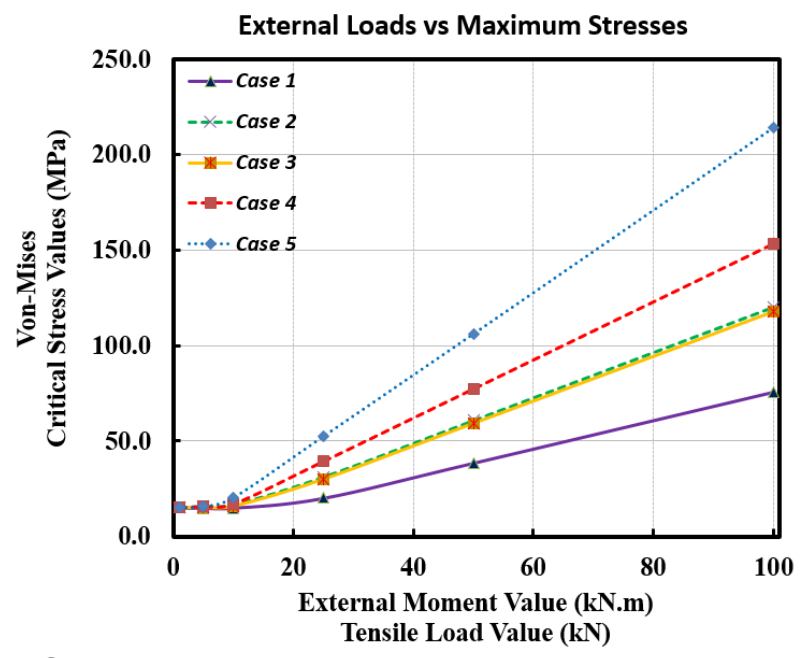

FIGURE 17: MAXIMUM STRESS VALUES UNDER VARIOUS EXTERNAL LOADS

\section{RESULTS AND DISCUSSION}

In the finite element method applications, the stress analysis of cylinder-cylinder connections is a very challenging engineering problem. For this purpose, a high-fidelity model study was developed in this paper. This study was based on one of the current models in the Chandiramani's study [10] and validation analyzes were performed on this model. As a result of these validation analyzes and calculations, the finite element model was deemed to give the correct results.

Thereafter, mesh sensitivity analyzes were performed in the same loading conditions and the most suitable number of elements were determined. Since the maximum stress values in the model occur at the nozzle junction, this sensitivity analyzes were performed based on the number of elements extending along the nozzle. As a result of these analyzes, it was revealed that the number of elements extending along the nozzle has no great effect on the stress values.

Then, some parametric studies were performed on the verified model. The main goal in these studies was to reasonably reduce the stress values in the cylinder-nozzle junction. Firstly, the model crotch corner was applied a $5 \mathrm{~mm}$ inner radius, which resulted in a reduction of $10 \%$ in stress values. These differences were reduced about until 2 percent when the cylinders' diameter was increased. These results showed that the dimensions of the outer welding fillet and inner radius should be examined separately. 
In doing so, analyzes were made on the change of welding dimensions. It was seen that the weld size is not very effective in reducing the stress in models with under internal pressure only. Following these analyzes, inner radius dimensions were increased. As a result, the maximum stress values decreased by up to $10 \%$ and the most suitable welding dimensions and inner radius sizes were determined.

In the final step of the parametric studies, the model was exposed to various external loads. A total of 5 different cases were examined and the results were shown in Figure 17. The important point in these analyzes was the change of the maximum stress point as the effect of external pressure increases. The internal pressure effect was more repressive than the external load effect in the first 3 loading magnitudes for each cases examined. For this reason, the maximum stress zone was on the crotch corner. The compression and tensile stress becomes more dominant as the external moment value was increased. In this case, the maximum stress zone was located on the weld itself as shown in Figure 18.

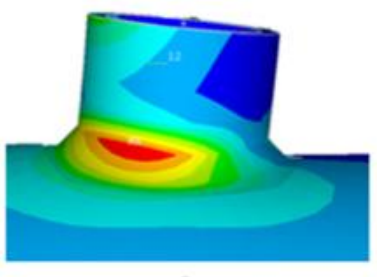

a

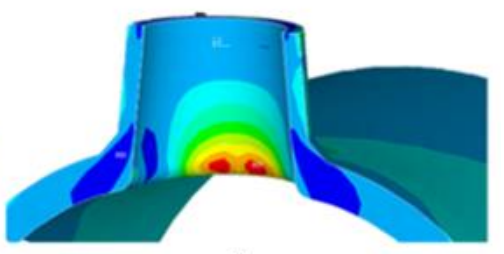

b
FIGURE 18: a)THE EFFECT OF EXTERNAL MOMENT IS MORE DOMINANT THAN THE INTERNAL PRESSURE EFFECT, b) THE EFFECT OF THE INTERNAL PRESSURE EFFECT IS THE MORE DOMINANT THAN THE EXTERNAL MOMENT.

In addition to these analyzes, the maximum stress values occurred in the models due to the tensile stress, longitudinal, and circumferential moment effect of were compared with the calculations in the WRC 537 bulletin. These comparison results can be seen in the Tables 2,3 and 4 . These results are only used for the values of $25 \mathrm{kN}, 50 \mathrm{kN}$, and $100 \mathrm{kN}$ since the moment effect is evident especially in the cases of $10 \mathrm{kN}$ and overload loading.

TABLE 2: COMPARISON OF MAXIMUM STRESS RESULTS FOR MODEL UNDER TENSILE LOADING

\begin{tabular}{|c|c|c|c|c|}
\hline & \multicolumn{2}{|c|}{ Magnitude } & \multicolumn{2}{c|}{$\begin{array}{c}\text { Maximum Stress Values } \\
\text { (Von Mises) }\end{array}$} \\
\hline Load type & $\begin{array}{c}\mathrm{P}_{\text {int }} \\
(\mathrm{MPa})\end{array}$ & $\begin{array}{c}\mathrm{P} \\
(\mathrm{kN})\end{array}$ & $\begin{array}{c}\text { FEA } \\
(\mathrm{MPa})\end{array}$ & $\begin{array}{c}\text { WRC 537 } \\
(\mathrm{MPa})\end{array}$ \\
\hline \multirow{3}{*}{ Tensile Load } & 0.5 & 25 & 20.11 & 20.10 \\
\cline { 2 - 5 } & 0.5 & 50 & 38.47 & 38.31 \\
\cline { 2 - 5 } & 0.5 & 100 & 75.67 & 75.62 \\
\hline
\end{tabular}

TABLE 3: COMPARISON OF MAXIMUM STRESS RESULTS FOR MODEL UNDER CIRCUMFERENTIAL MOMENT LOADING

\begin{tabular}{|c|c|c|c|c|}
\hline & \multicolumn{2}{|c|}{ Magnitude } & \multicolumn{2}{c|}{$\begin{array}{c}\text { Maximum Stress } \\
\text { Values (Von Mises) }\end{array}$} \\
\hline Load type & $\begin{array}{c}\mathrm{P}_{\text {int }} \\
\mathrm{MPa})\end{array}$ & $\begin{array}{c}\mathrm{M}_{\mathrm{C}} \\
(\mathrm{kN} . \mathrm{m})\end{array}$ & $\begin{array}{c}\text { FEA } \\
(\mathrm{MPa})\end{array}$ & $\begin{array}{l}\text { WRC 537 } \\
(\mathrm{MPa})\end{array}$ \\
\hline $\begin{array}{c}\text { Circumferential } \\
\text { Moment }\end{array}$ & 0.5 & 25 & 31.06 & 33.20 \\
\cline { 2 - 5 } & 0.5 & 50 & 60.7 & 66.4 \\
\cline { 2 - 5 } & 0.5 & 100 & 120.1 & 132.8 \\
\hline
\end{tabular}

TABLE 4: COMPARISON OF MAXIMUM STRESS RESULTS FOR MODEL UNDER LONGITUDINAL MOMENT LOADING

\begin{tabular}{|c|c|c|c|c|}
\hline \multirow{2}{*}{ Load type } & \multicolumn{2}{|c|}{ Magnitude } & \multicolumn{2}{c|}{$\begin{array}{c}\text { Maximum Stress } \\
\text { Values (Von Mises) }\end{array}$} \\
\hline \multirow{2}{*}{$\begin{array}{c}\text { Longitudinal } \\
\text { Moment } \\
\text { MPa }\end{array}$} & $\begin{array}{c}\mathrm{M}_{\mathrm{L}} \\
(\mathrm{kN} . \mathrm{m})\end{array}$ & $\begin{array}{c}\text { FEA } \\
(\mathrm{MPa})\end{array}$ & $\begin{array}{c}\text { WRC 537 } \\
(\mathrm{MPa})\end{array}$ \\
\cline { 2 - 5 } & 0.5 & 25 & 30.05 & 31.21 \\
\cline { 2 - 5 } & 0.5 & 50 & 59.32 & 62.42 \\
\hline
\end{tabular}

As can be seen in the Tables 2-4, the results are almost the same, especially in cases where the model under only tensile loading. For the models where the longitudinal and circumferential moment is applied, the differences are nearly 5 percent. The close results obtained once again demonstrate the correctness of the model. Whilst this gives confidence that WRC 537 is conservative for the moment cases, it is over predicting the maximum stress which can have an influence when using these stresses for fatigue life evaluation.

\section{CONCLUSIONS}

As a result of these studies, a validated high fidelity model has been developed. This model has been shown to give the correct results as can be seen in Figure 6. In addition, as a result of the detailed changed to the inner and outer welding fillet modifications made on the finite element model, it is provided to give more physically realistic results than those currently available in the published literature.

In order to be able to address a larger range of problems to this model, reinforcement plate applications, limit load and shakedown load analyses are planned. The model can also be developed with multiple nozzle geometries and vessel with pad configurations. At the end of all these studies, the aim is to develop a universal approach which can respond to many cylinder-cylinder assembly configurations.

\section{ACKNOWLEDGEMENTS}

The first author was supported by the Republic of Turkey Ministry of National Education (MoNE-1416/YLSY).

\section{REFERENCES}

[1] Wichman, K.R., Hopper, A.G. and Mershon, J.L. "Local Stresses in Spherical and Cylindrical Shells Due to External Loadings." Welding Research Council Bulletin No. 107. New York (2002) 
[2] Wichman, K.R., Hopper, A.G. and Mershon, J.L. "Precision Equations and Enhanced Diagrams for Local Stresses in Spherical and Cylindrical Shells Due to External Loadings for Implementation of WRC Bulletin 107" Welding Research Council Bulletin No. 537. (2013)

[3] Mershon, J.L., Mokhtarian, K., Ranjan, G.V. and Rodabaugh, E.C. "Local Stresses In Cylindrical Shells Due To External Loadings On Nozzles-Supplement to WRC Bulletin No. 107 (Revision I)" Welding Research Council Bulletin No. 297. (1984)

[4] BS 5500:1991, "G.2.2., Radial loads on cylindrical shells, G.2.3 -External moments applied to cylindrical shells." British Standards Institution, London, (1991)

[5] Wordsworth, A. C., "Stresses in cylindrical pressure vessels due to local loads." In Structural Integrity Assessment. London, (1992)

[6] Dekker, C.J. "External Loads on Nozzles." International Journal of Pressure Vessels and Piping Vol. 53 (1993): pp. 335350 .

[7] Dekker, C.J. and Bos, H.J. "Nozzles — on External Loads and Internal Pressure. "International Journal of Pressure Vessels and Piping, Vol. 72, (1997): pp. 1-18.

[8] Sedighiani, K., Mosayebnejad, J. and Mafi, M. "Fracture Analysis of a Semi-Elliptical Crack in a Nozzle-Vessel Junction Under External Loads." Proceedings of the Institution of Mechanical Engineers, Part C: Journal of Mechanical Engineering Science, Vol. 226 No.4 (2012): pp:871-886.

[9] Andrade, Tatiana Lima., Paula, Wagner Andrade de. and Junior, Pedro Americo Almeida Magalhaes. "Analysis of Stress in Nozzle/Shell of Cylindrical Pressure Vessel under Internal Pressure and External Loads in Nozzle." International Journal of Engineering Research and Applications Vol.5 No.9 (2015): pp. 84-91.

[10] Chandiramani, Dipak., Gopalakrishnan, Shyam. and Mathkar, Ameya. "Effect of Nozzle Dimensions on The Stresses in Compensated Openings in Cylindrical Shells." Proceedings of the ASME 2015 Pressure Vessels and Piping Conference PVP2015-45564: Boston, Massachusetts, USA, July 19-23, (2015)

[11] Fang, J., Tang, Q.H. and Sang, Z.F. “A Comparative Study of Usefulness for Pad Reinforcement in Cylindrical Vessels Under External Load On Nozzle.” International Journal of Pressure Vessels and Piping Vol.86 (2009): pp.273-279. 